\title{
ARTICLE
}

\section{Development of foundation year 1 psychiatry posts: implications for practice}

\author{
Rachel Steele \& Sharon Beattie
}

\begin{abstract}
Rachel Steele is a clinical librarian. Her main interests include the emerging role of the clinical librarian/informationist to lead and facilitate access to the evidence base in all aspects of mental health services as well as educational/ continuing professional development interventions to develop health professionals' skills in using evidence in their practice. Sharon Beattie is a specialty registrar in general adult psychiatry. She has a strong interest in medical education and took a year out of training to undertake the post of Medical Education Teaching Fellow. At the time of submission, both authors work for Tees, Esk and Wear Valleys NHS Foundation Trust.

Correspondence Rachel Steele, Library and Information Service, Tees, Esk and Wear Valleys NHS Foundation Trust, Education Centre, Lanchester Road Hospital, Durham DH1 5RD, UK. Email: rachelsteele@ nhs.net
\end{abstract}

\begin{abstract}
SUMMARY
Most literature discussing the introduction of foundation year 1 (F1) psychiatry posts has focused on recruitment. However, for F1 posts to offer a valuable learning experience and a potential recruitment boost, psychiatrists and employing organisations should be aware of general issues arising in the first postgraduate year. These include the inherently stressful student-todoctor transition, the need for bespoke induction programmes for new graduates, F1 doctors' specific needs for support, supervision and peer support, and the centrality of the relationship with the consultant supervisor to the new doctor. Understanding these themes will enable psychiatrists and mental health organisations to offer better F1 psychiatry experiences, which may boost recruitment and could maximise the opportunities for F1 doctors to develop skills and qualities that will be of value in their future careers, whatever specialty they end up working in.
\end{abstract}

\section{DECLARATION OF INTEREST}

None.

The phrase 'recruitment crisis' in psychiatry is unfortunately not an alien concept, with the number of UK graduates entering psychiatry not matching workforce needs. In fact, recruitment 'crisis' is perhaps a misnomer, as recruitment into psychiatry has been consistently low at around 4\% of UK graduates since the 1970s (Goldacre 2005). In the past, overseas recruits to the specialty have compensated for low uptake by UK medics. However, recent changes in immigration law and visa requirements have unmasked the recruitment deficit among UK graduates. The Department of Health has argued that 'psychiatry is a recruiting, not a selecting speciality' (Department of Health 2004). This reflects the concern that low numbers of applicants for psychiatry posts may make it difficult to recruit only the 'best' and most suitable medical graduates. Furthermore, low numbers in training schemes may have a negative impact on service provision and those who do enter training.
With the Royal College of Psychiatrists launching its recruitment strategy, it is clear that solutions to the problem are multidimensional, which reflects the complex causality (Brown 2012). From the existing literature, it is apparent that undergraduate experiences are important in influencing future career intentions (Manassis 2006; Brown 2007; Eagles 2007). Students' attitudes and intentions towards psychiatry can be positively influenced, particularly by clinical experiences, irrespective of prior intentions (McParland 2003). However, it has been shown that these positive changes can be eroded over time and following graduation (Maidment 2004). This is important as we know that doctors who do embark on a career in psychiatry tend to make this decision after graduating (Moloney 2000; Brown 2007; Dein 2007). This is not unique to psychiatry. Doctors' career decisions change after graduation with the first 3 postgraduate years forming a seemingly critical period (Mahoney 2004; Goldacre 2005).

\section{Work experience}

In specialties other than psychiatry, the most important influencing factor on career path is work experience in the first postgraduate year. By the third postgraduate year, however, experience of jobs undertaken so far becomes as important for those choosing psychiatry as it is for other specialties (Goldacre 2005). The differing picture in psychiatry may be due to the relative poverty of psychiatry posts early within the postgraduate training period, with potential recruits being tempted away by positive experiences in other specialties. This is important as training has become more streamlined in the past 8 years and doctors are being asked to make career choices earlier in their careers than historically may have been the case. The recent increase in fees that medical students must pay, alongside the relative decrease in pay due to compliance with the European Working Time Directive may also deter junior doctors from specialty shifting 
once they have entered training. This potentially makes early postgraduate experiences all the more important in influencing career trajectories.

\section{Training and recruitment}

The Foundation Programme was introduced in 2005 and forms the bridge between medical school and specialty training. It generally consists of six posts over the 2-year programme. Until recently the proportion of posts within psychiatry has been low, with an audit in England showing only 3.5\% of foundation posts to be in psychiatry, a number which does not map to the future workforce needs (Lowe 2012). It has been reported that undertaking a psychiatry placement as a foundation doctor may make the specialty more attractive as a career choice (Shah 2011). Foundation doctors in the UK who had experience of psychiatry (both via placements or via tasters) during the Foundation Programme were 8.19 times more likely to choose the specialty as a career than foundation doctors without such experiences, although it is not clear whether the doctors choosing psychiatry already had prior career intentions towards the specialty (Kelley 2013).

In a cohort study of the career choices of UK medical graduates, Goldacre et al (2013) likewise argue that offering more exposure to psychiatry during foundation training may boost recruitment. Following the Collins review (Collins 2010) and in response to recruitment issues within psychiatry, the Royal College of Psychiatrists have recommended that $7.5 \%$ of foundation year 1 (F1) posts should be in psychiatry for the 2013 intake, with $22.5 \%$ of $\mathrm{F} 1$ trainees rotating through a placement in psychiatry (Brown 2012). Box 1 gives an explanation of the acronyms used in this article relating to the first 2 years of medical practice.

\section{Advantages of F1 posts}

As well as the potential positive implications F1 posts may have on recruitment, psychiatry placements provide an opportunity to reach a wider group of doctors. These placements arguably offer a unique opportunity for the future education and development of all doctors, and will be valuable in whatever specialty these F1 trainees eventually choose to work.

In addition to the obvious benefits of being competent in recognising, assessing and managing patients with mental disorders, psychiatry posts provide the opportunity to further develop other attributes which are crucial in modern medicine. The public desire doctors who have good communication skills and who do not adopt patronising, paternalistic or arrogant attitudes
BOX 1 Definitions of acronyms used in this article relating to the first 2 years of medical practice
PRHO (pre-registration house officer)

Prior to 2005, in the UK, new doctors in their first postgraduate year were called pre-registration house officers. This title indicated their registration status with the GMC and they were required to work under supervision.

\section{SHO (senior house officer)}

Doctors who successfully completed the PRHO year and gained full registration with the GMC then took up posts as senior house officers. They worked at this level for a variable number of posts (usually for several years), depending on their capabilities, preferences and the job opportunities available, before entering advanced training.
F1 (foundation year 1)

This replaced the PRHO year in 2005 and is the first year of the 2-year Foundation Programme.

Following successful completion of the F1 year (which includes attaining full registration with the GMC), doctors then progress to the second year of postgraduate training. Before being eligible to move on to specialist core training, they must successfully complete this second year of the Foundation Programme.

Foundation trainee/foundation doctor A generic term for a doctor in either $\mathrm{F} 1$ or $\mathrm{F} 2$.
F2 (foundation year 2)

towards their patients. They require doctors who allow for, and respect, patient autonomy; who are committed to addressing poor practice and to accepting more accountability (Irvine 1999). It has been argued that these patient-led demands should merit a concerted response from the profession: this response can be termed 'the new professionalism' (Irvine 1999). A psychiatry placement offers significant opportunities for F1 doctors to begin the process of responding to the challenges afforded by the new professionalism and to develop behaviours which are conducive to public perceptions of the qualities required to be a doctor. Box 2 explores the opportunities a psychiatry placement may offer the F1 trainee in this area.

\section{Dilemmas and challenges}

Despite the potential benefits of the expansion of F1 psychiatry posts, the situation does create a dilemma for the specialty. There is a desire to improve recruitment and experiences of psychiatry, and any strategy which may contribute towards this agenda is attractive. There is, however, a lack of experience in some areas in facilitating F1 posts. Foundation doctors differ significantly in clinical experience from psychiatric trainees who have traditionally worked with relative autonomy. Anyone who can remember moving from medical school into the 'real world' appreciates that this is an exciting but anxiety-provoking time. Anecdotally, it seems that most new graduates just want to master what they see as the core survival skills, enabling them to keep their patients alive 
BOX 2 Added benefits of F1 psychiatry posts in promoting the characteristics of 'new professionalism'

- The doctor-patient relationship. The GMC advocates relationships based on openness, trust, good communication and partnerships between all doctors and their patients (General Medical Council 2013). This way of relating to patients is, and has long been, central to practising as a psychiatrist.

- A more balanced relationship between doctors and patients (avoiding paternalism, arrogant behaviours, etc.). The collaborative nature of psychiatric clinical work between the doctor and patient is highly conductive to this approach.

- Treating patients with dignity and avoiding discrimination. Psychiatrists have been engaging with these issues for many years (e.g. by advocating for the needs of those with mental health problems and speaking out to end stigma and discrimination against their patients).

- Working effectively within teams. The way of working in mental health multidisciplinary teams can offer an F1 doctor experience which will help pave new recruits' approach to working within clinical teams no matter what their future career.
- Skills in managing patients with medically unexplained symptoms. This issue has long been recognised in psychiatry, with particular branches of the specialty (e.g. liaison psychiatry) developing key expertise. The government estimates that medically unexplained symptoms cost the National Health Service in England $£ 3$ billion annually and that individuals with medically unexplained symptoms have at least $50 \%$ more frequent contact with primary care clinicians and up to $33 \%$ more secondary care consultations than the general population (HM Government 2011).

- Awareness of the importance of selfcare. Doctors in all specialties are encouraged to be aware of their own mental health and to avoid developing behaviours which may lead to stress, burnout, physician impairment or becoming a dysfunctional doctor. Although psychiatrists do not always practise themselves what they advocate for patients or colleagues in terms of self-care, F1 doctors who undertake a mental health placement will have a greater understanding of the prevalence of mental disorders and how to manage and recognise mental disorder/ stress in themselves and others. and giving them a solid basis as a doctor. So how does psychiatry fit into this? Psychiatry F1 posts that have existed previously have tended to serve a self-selected group of 'psychiatry sympathetic' F1 doctors who already want to pursue it as a career. Introducing psychiatry posts as the norm as opposed to the exception potentially raises challenges.

So as we are faced with a rise in psychiatry F1 posts, a number of questions arise. How can we maximise the success of these posts? What problems can we anticipate? How can we preempt these? We have explored the literature in an attempt to address these questions, and to learn from the themes that have arisen. Unfortunately, there has been little opportunity to learn from experiences of other specialties (such as pathology and radiology) in which traditionally low numbers of pre-registration house officers (PRHOs) or F1 posts have subsequently increased, as there is limited research in this area (Ford 2010; Ip 2010; Hung 2011).

\section{Stress, the F1 year and working in psychiatry}

Studies have highlighted that the first year of medical practice may be particularly stressful. (Bogg 2001; Paice 2002a; Tyssen 2002; Milstein 2009). There is a general consensus among many authors that the inherently stressful nature of the transition from student to doctor is responsible for this. Factors which may contribute towards this process include (Bogg 2001; Paice 2002a):

- difficulties in developing a sense of 'professionalism'

- organisational factors such as frequently moving work base

- perceptions of excessive responsibility

- administrative factors (the requirements to complete official paperwork as a newly qualified doctor)

- high levels of emotional stress from specific clinical duties such as breaking bad news and communicating with relatives.

Numerous studies have highlighted how doctors in general have greater psychiatric morbidity and burnout than the general population (Ramirez 1996; Taylor 2005). Research has also highlighted that psychiatrists may be particularly prone to stress and burnout (Fothergill 2004). There is no clear consensus of the reasons for this phenomenon, but a persuasive model of factors influencing stress in psychiatrists is shown in Box 3 (Kumar 2005). Precipitating factors in this model have particular implications for F1 posts. If stressful external events can cause those at consultant level to experience such distress, then we may infer how much more challenging it may be for F1 doctors to cope with these factors coupled with other stressors associated with the first year as a qualified doctor. It should be acknowledged, though, that the experience of stress is specific to the individual and that the relative influence of predisposing, precipitating and perpetuating factors will vary between people.

BOX 3 Model of how psychiatrists cope with and interact with stress

Kumar (2005) argues persuasively for the existence of:

- predisposing factors (the combination of psychiatrists' personalities with their clinical work)

- precipitating factors (external stressors in psychiatrists working lives)

- perpetuating factors (the development of negative coping mechanisms) that influence how psychiatrists cope with stress 


\section{Suicide of a patient}

The range of external stressors that may affect psychiatrists is extensive, but one of the more extreme stressful events is the suicide of a patient (Fothergill 2004; Kumar 2005; Kelleher 2011). Despite this issue being of significant concern to practitioners, the evidence base examining the effects on psychiatrists is limited. A recent study reported that after the attempted suicide of a patient, 'trainees were more likely than consultants to experience psychological pain, guilt, self-doubt, and frustration' (Scocco 2012: p. 94). In addition to these less frequent extreme outcomes, there are many other significant work stressors in psychiatry which, although present in other specialties too, can cause significant concern to junior doctors in psychiatry. These include dealing with violent patients, hostile relatives and on-call duties (Guthrie 1999; Rathod 2000).

\section{Consultants' stress}

Although junior doctors in psychiatry tend not to have to manage the same degree of uncertainty and ultimate responsibility as senior doctors (Fothergill 2004), there is some evidence that despite this, junior staff may be more likely to experience stress and burnout than senior colleagues (Guthrie 1999; Kumar 2005). With these factors in mind it may also be prudent to consider carefully what is communicated to $\mathrm{F} 1$ doctors while they are already managing new experiences and different potential sources of stress. Modernisations such as changes to mental health service delivery have been found to reduce consultant stress, but some studies have identified that there are predominantly negative attitudes within the profession to New Ways of Working (Malik 2008; Dale 2009; St John-Smith 2009; Rathod 2011).

It needs to be considered how junior trainees might perceive such attitudes if they are present (e.g. by observing consultants who seem demoralised or express negative attitudes about their current working conditions). Such observations may potentially form an additional external stressor. If modernisations in psychiatry confuse junior doctors as to the doctor's role (and therefore their own role) in the seemingly flatter hierarchy in psychiatric clinical teams (compared with surgery and general practice), this may form a further stressor (Mukherjee 2013).

\section{Pre-registration status}

A further consideration is the pre-registration status of F1 doctors and the impact this has on the work they can do. Owing to the tasks involved (such as designated deputy for the purpose of the Mental Health Act 1983) and the relative lone working of junior doctor on-call rosters, most F1 doctors are unlikely to be included on outof-hours on-call rosters. The 'normal' stressors that junior doctors in psychiatry are exposed to include making risk assessments and management plans when on call. Such risk-taking/tolerance tasks may traditionally be seen as an external stressor. However, paradoxically, if F1 trainees are not exposed to such potentially stressful yet challenging and satisfying tasks, then this may be a source of frustration/dissatisfaction.

There is a danger that the General Medical Council (GMC) registration status of F1 doctors could mean that they are signposted largely to administrative duties in their psychiatry placements rather than given real experience of clinical work. It has previously been reported that senior house officers (SHOs) were dissatisfied with psychiatry placements because they felt they were expected to act mainly as clerks on inpatient units (Pidd 2003). Careful consideration needs to be given to the role of the F1 doctor within the team, and the impact this has on their learning and satisfaction. To take a wider perspective, the expertise and literature on motor learning theoretically supports the argument that providing too much guidance to junior doctors could be educationally detrimental in the longer term, and that this group should be allowed to exercise autonomy as they become more clinically competent (Kennedy 2005).

It is therefore vital that F1 doctors are allowed opportunities to develop clinical skills (as far as their GMC registration status allows) and are given enough freedom and autonomy to act as developing practitioners. Perception of job content is also important as it can affect career choice. A cohort study of UK medical graduates' career choices demonstrated that $72 \%$ of those who had initially chosen psychiatry but then rejected it attributed their decision to 'job content', compared with $33 \%$ of doctors who considered but then rejected other specialties (Goldacre 2013).

\section{Recruitment into psychiatry}

The discussion about stress experienced by F1 doctors in general, and in psychiatry specifically, is of relevance to the discussion about recruitment into the specialty. Previous research (Lambert 2006) has shown that doctors who initially chose psychiatry as a career, but then decided to leave, tended to attribute their decisions primarily to internal factors (i.e. self-assessed unsuitability, perceptions of job stress and concerns about lack 
of evidence-based treatments) rather than external factors (perceived poor image of specialty and perceived lack of respect by medical peers). These internal factors were also reported as key for those rejecting psychiatry in the first post-qualification year (Lambert 2003). The foundation curriculum may provide opportunities for new graduates to acquire knowledge of psychiatry so as to make more informed career choices (Lambert 2006). However, there is a potential danger that F1 doctors may misattribute some of the general stressors that are prevalent in the first year of clinical practice to the work of a psychiatrist, so that they may 'internally' self-assess themselves as unsuitable for psychiatric work.

\section{Physician impairment}

In addition to careful planning and consideration of the content of foundation posts, those who will be supervising $\mathrm{F} 1$ doctors should provide guidance and pastoral support to aid them in distinguishing the potential stressors when working in psychiatry from the separate stressors inherent in the first foundation year. Open acknowledgement and discussion of such issues may help promote the development of positive coping strategies.

The importance of supporting F1 doctors in accommodating to the reality of the first year of clinical practice is highlighted in a study of psychiatric trainees which introduces the concept of 'physician impairment' (Kozlowska 1997). An 'impaired physician' is 'unable to fulfil professional or personal responsibilities' (p. 629). This process starts early in professional life, resulting from doctors' neglect of their own physical and emotional issues and inability to balance personal and professional roles (i.e. a perpetuating factor in stress and burnout) (Kumar 2005; Box 3). Rates of impairment range from 16 to $27 \%$ among junior doctors in all specialties and between 9 and $22 \%$ in psychiatry trainees specifically (Kozlowska 1997). Although these figures suggest lower rates in psychiatry trainees, this sample did not include $\mathrm{F} 1$ doctors in psychiatry.

\section{The role of induction}

Foundation doctors have expressed concerns about a lack of preparation for the specific context of psychiatry in terms of required knowledge/ clinical skills and understanding of mental health team structures (Welch 2011). These issues, along with managing trainees' initial anxieties, could be remedied by thoughtful induction programmes. The literature provides examples of how effective inductions can compensate for limited exposure to specialties during undergraduate training. For example, "All training placements should start with a detailed "educational needs assessment" and identification of clear learning objectives for the placement' (Kilminster 2007: p. 12). If F1 doctors were to be surveyed nationally regarding their learning needs in psychiatry placements (particularly their confidence in psychiatric clinical skills), then this would be valuable data which could inform trust induction programmes.

An interesting example is an induction programme designed to develop clinical skills to remedy perceived omissions in the undergraduate training of dental compared with medical trainees taking up SHO hospital dentistry posts (Stark 2003). The position of these dental trainees could be analogous to F1 doctors undertaking a psychiatry placement because dental trainees' undergraduate experiences may not have provided them with the range of clinical skills that a medical graduate may have developed. Similarly, a medical degree may have a limited psychiatry component, so a graduate may not have the level of mental health knowledge and clinical skills desirable for working as a foundation doctor in psychiatry. Mental health organisations therefore should provide robust training, support and supervision in basic psychiatry clinical skills for F1 doctors early in their appointments.

An innovative report of a successful induction encompasses involvement from departing PRHOs (Gale 1992). Involving other foundation/junior doctors in the induction process for F1 doctors may reduce anxiety about starting in a new work base and in a specialty which may appear different from much of their clinical undergraduate experiences.

Another important theme is the need to make a distinction between trainees' immediate, practical needs as they start a new job and the needs of the organisation. A successful example is an SHO induction programme divided into essential service information and more generic education (Ward 1999a,b). It may be advisable to induct psychiatry F1 doctors into their day-to-day work base straight away but to provide education/ training when immediate practical anxieties have lessened. Box 4 highlights some factors which may contribute to a successful induction.

\section{Integration with other specialties and the general importance of peer support}

Owing to the physical separation of many mental health and acute trust premises, and the ways of working in psychiatry, there has been concern about foundation trainees feeling geographically isolated from peers while working in psychiatry. For this reason, Welch et al (2011) suggest that 
foundation trainees should maintain links with the acute hospital and 'medical' peers by doing on-call work in acute hospitals while working in psychiatry. However, literature discussing general problems which can occur during the first year of medical practice suggests that the idea of F1 doctors undertaking on-call work in acute hospitals while doing psychiatric placements may not be as attractive as it initially appears. In a sample of PRHOs, a group completing a 1-year placement was significantly less stressed than trainees completing the standard 6-month placement. These differences may be due to geographical and occupational stability (Firth-Cozens 2000). Thus, if psychiatry F1 doctors were required to work simultaneously in two organisations and with two different sets of colleagues, this in itself may be enough to put this group under significant pressure, irrespective of the demanding nature of acute hospital on-call duties.

The idea of continuing work on the acute oncall rota does, however, have the advantage that F1 trainees could maintain more formal links with peers in other specialties. Indeed, the importance of peer support as a means of combating the difficulties F1 doctors may experience in adapting to medical practice is stressed in the literature: the use of "various forms of social support at the workplace' and 'appropriate socializing outside of the workplace[...] is likely to be very important in helping young physicians to manage workplace and life stressors' (Tyssen 2002: p. 163). The importance of social/peer support should therefore be recognised when identifying where these new posts are located and when putting in place structural supports for F1 psychiatry trainees. A solution which may be effective could be to pair up F1 doctors with other junior psychiatrists in a 'buddy' system. This would foster more formal peer support mechanisms while avoiding potential pitfalls which could ensue with continuing acute hospital on-call work.

Another idea would be to give F1 trainees specific responsibilities for undertaking psychiatric liaison on-call work in the acute hospital. This would support curriculum competency development (such as the UK Foundation Programme curriculum syllabic outcome 8.6: 'manages acute mental disorder and self-harm') while providing opportunity to meet peers in the acute hospital environment (UK Foundation Programme 2012). Such a roster would need to be carefully constructed to ensure that there was adequate support and supervision. In many areas, liaison teams have extended their hours of working and so foundation trainees could be integrated into
BOX 4 Factors that need to be considered when designing induction programmes for F1 psychiatry placements
- Training and guidance for supervisors to help F1 doctors acquire core psychiatric clinical skills which may not have been fully covered in their undergraduate training

- Consider involving departing F1 doctors (or other junior doctors) in the induction of new $F 1$ recruits (a short informal guide from the departing doctor on 'the things I wish I had been told when I first started this job')

- Avoid overloading trainees with excessive amounts of information

- Separate F1 doctors' immediate, practical needs in their new posts from deeper educational or clinical induction, and stagger the induction process appropriately so as not to delay integration into the clinical area

- Orientation and guidance about immediate practical working conditions and clinical duties should take place as soon as the
F1 doctor begins their post; introduction to other aspects of the organisation (e.g. clinical audit, library and information services) should be delayed for a few weeks, until the trainee has become more accustomed to their new role

- Careful planning and management of the administrative load will help maximise the clinical experience and reduce stress; for example, F1 doctors could receive tailored guidance from a 'buddy' psychiatry trainee about the administrative requirements of their role and they could ask their consultant supervisor to discuss this issue early in their planned sessions of educational supervision

- Providing clarification to F1 doctors and allied staff as to the expected level of responsibility is vital - this may be in the form of welcome booklets for trainees and education for other staff through ward briefings or the equivalent these teams where they would be well supported and supervised. This may also allow the F1 doctor to do out-of-hours working, while remaining well supported.

\section{Support and supervision}

As well as F1 trainees' needs for support from peers, these trainees also require significant support and supervision from consultant psychiatrists. Those providing supervision and support should be mindful that junior trainees are likely to learn vicariously from respected seniors, so there is a need for consultant behaviours to match the guidance they are giving to trainees. The role of the consultant supervisor is recognised as a potentially pivotal influence to trainees generally, as this relationship 'could make the difference between setting out positively in their career or making the decision to leave medicine' (Paice 2002a: p. 26). The quality of the relationship between consultants and trainees and poor quality supervision have been cited as major factors that deter SHOs from pursuing a longer-term career in psychiatry (Pidd 2003).

In British psychiatric training there has been a long history of providing consultant-facilitated one-to-one educational supervision to trainees. This 1-hour weekly supervision can be seen as a 
real strength of these placements. However, as this is not a requirement of the foundation curriculum, it may be tempting for busy consultants who have more than one trainee not to provide $\mathrm{F} 1$ trainees with this level of input. Nevertheless, educational supervision does provide the ideal opportunity to address many issues raised in this article.

In addition to considering the continuation of weekly educational supervision, equally important is the source of on-the-job clinical supervision. If the role of the consultant supervisor can make such a significant difference to F1 doctors' views of medicine as a career, then the fact that clinical supervision for psychiatry foundation trainees is often being provided by non-medics may reinforce perceptions that working in psychiatry is fundamentally different to other medical specialties (Welch 2011). Although peer and multidisciplinary team support may be appropriately provided from other professional groups, the complex issues we have identified so far suggest that the role of a senior medical supervisor in providing core clinical supervision, as well as pastoral support, is fundamental to making $\mathrm{F} 1$ posts an educational and recruitment success.

\section{Challenges for F1 supervisors}

A theme which has been somewhat underemphasised in the literature discussing the introduction of foundation psychiatry posts is the implication that this change may have for those with responsibilities towards F1 doctors. The arrival of a more diverse and junior group of doctors may provide new challenges for supervisors.

\section{Role modelling}

The general medical education literature offers some salient points. Role modelling is well recognised as an important part of the 'hidden curriculum' in both postgraduate and undergraduate medical education (Harden 2000; Azer 2005; General Medical Council 2009). Relating to this is the emotional dimensions which may be involved in the rapport between supervisor and supervisee (MacDougall 2005; Sutkin 2008; Stenfors-Hayes 2011). It is unclear exactly which qualities may be required in senior doctors to make them positive role models. The literature does, however, suggest that being a successful clinical teacher may depend more on 'non-cognitive' skills. These relate to a teacher's personal qualities such as their relationship/communication skills, personality types, ability to embody 'positive' qualities such as enthusiasm, and investing in the doctor-patient relationship and their being patient and showing integrity (Sutkin 2008; Jochemsen-van der Leeuw
2013). These are some of the key qualities which have been identified as requisite for doctors seeking to meet the challenge of the new professionalism (Irvine 1999). Role modelling is likewise central to effective teaching in medical education (Harden 2000; Paice 2002b).

The processes involved in role modelling and the emotional dimension between supervisor and supervisee are nebulous and hard to capture. Further research is needed to clarify to what extent these factors do make a difference in career choice. However, if psychiatry supervisors feel that F1 doctors are not receptive to their specialty or have negative perceptions of their clinical work, then this may affect the supervisory relationship and they may be less able to display behaviours which make them effective role models.

Supervising F1 trainees is fundamentally different from supervising more senior trainees. Foundation doctors may not yet have had a chance to develop the 'clinical mindlines' which enable doctors to work at a more advanced level in reallife practice, without the extensive reference to the theoretical basis of medicine which is necessary as a medical student and new trainee (Gabbay 2011). Consultant supervisors must be aware of the limits of F1 doctors' current skill and knowledge base.

\section{Scaffolding}

The theory of scaffolding in medical education is key here. Scaffolding is a metaphor which 'refers to the temporary support provided for learners to help them complete a task they would otherwise not be able to complete on their own' (Schmidt 2011: p. 797). 'Soft' scaffolds, which can be provided verbally during supervision (distinct from 'hard' scaffolds such as generic written support), should be tailored to the needs of the trainee so as to provide support only when needed. Foundation year 1 doctors will have a greater need for scaffolds than more senior psychiatry trainees, but it is important that consultants are sensitive in their provision of scaffolds so as to allow the trainee the ability to grow in confidence and independence. This is consistent with our earlier argument that it may be educationally detrimental longer term to provide excessive amounts of guidance to junior trainees (Kennedy 2005).

\section{Planning supervision}

As well as the more ad hoc or informal support which supervising psychiatrists can offer to F1 doctors, supervisors should be prepared to plan a structured approach to educational supervision to help the trainee direct their study and acquire basic clinical skills. In general, learning objectives 
should be agreed at the start of a supervisory relationship (Kilminster 2007). The need to plan supervision sessions in advance (e.g. via producing an agenda for the meeting) is highlighted in the more general literature on supervision (Kilminster 2007; Munro Wickham 2012).

Planning appropriately for supervision sessions is not just the responsibility of the consultant supervisor. However, as educational supervision within psychiatry will be a new concept to the F1 doctor, the supervisor will need to guide them in setting the tone for a programme of supervision. Supervision is seen as 'given' by consultants and 'received' by foundation trainees, with the consultants in many cases not realising the full extent of the trainees' supervision needs (Ho 2004). However, there is some evidence that supervision is only successful when supervisees control the 'product' of supervision (Kilminster 2007). Consultants should encourage the F1 doctor to use the supervision process as a dialogue in which the trainee plays a role in actively directing this dialogue to meet their learning needs.

Supervisors of foundation doctors need to be trained in providing supervision. It has been suggested that training for supervisors should include: 'understanding teaching, assessment; counselling skills; appraisal; feedback; careers advice; interpersonal skills' (Kilminster 2007: p. 2).

It could therefore be argued that the role of a supervisor should be a specialist one which only consultants with the requisite skills and/or training should fulfil. This should, however, be balanced by the fact that excessive prescription of requirements for a supervisor may contribute to consultant stress and may discourage consultants from taking on supervisory duties. However, if consultant supervisors are offered more guidance and structure from employing organisations in their supervisory role, this could be beneficial to both parties in reducing ambiguity about what is required for a successful supervisory partnership.

Box 5 summarises practical considerations that individual psychiatrists, employing organisations and professional bodies need to engage with to meet these challenges.

\section{Conclusions}

The introduction of foundation posts may well be an opportunity for recruitment into psychiatry. However, for this opportunity to be realised, mental health organisations and individuals with key roles in training F1 doctors need a thorough appreciation of the salient themes in the literature of the general foundation year experience as well as
B0X 5 Pre-empting problems and maximising the success of F1 psychiatry posts
- Peer support is vital to F1 doctors and careful consideration needs to be given to how to 'connect' these doctors with peers, to maximise peer support but minimise fragmentation of posts

- Employing organisations should consider implementing a 'buddy system' between $\mathrm{F} 1$ doctors and other junior doctors in psychiatry to foster more formal peer support mechanisms for new trainees

- Support from other professional groups in the multidisciplinary team is important, but clinical supervision should be provided by senior medical staff

- Supervisors should consider the potential impact of the increase in the number of foundation posts on the supervisory relationship, given that they will be faced with less experienced trainees who, in some instances, may be less 'psychiatry friendly' than more senior psychiatry trainees

- Supervisors should help F1 doctors differentiate the general stressors which may accompany the F1 year from stressors that may be specific to psychiatry of role modelling and the emotional
- Supervising psychiatrists should be aware dimension of the supervisor/supervisee

- Supervising psychiatrists should be mindful of the need to provide scaffolds to F1 doctors in a flexible, sensitive manner to balance the trainee's need for support with the need for them to develop as confident and able practitioners

- Mental health organisations and professional bodies should provide/ use practical guides to help supervising psychiatrists rather than solely relying on psychiatrists to be good supervisors

- Consideration should be given to developing an educational supervision template for F1 doctors; this should be compatible with the foundation curriculum but flexible for individual F1 needs

- Semi-structured educational supervision, with a planned programme of topics matched to competencies in the foundation curriculum and designed to address issues identified in this article, may help engage unenthusiastic trainees

- Educational supervision for F1 doctors should be conducted in the same way as it is for other psychiatry trainees and provided by consultant psychiatrists relationship

knowledge of the psychiatry-specific recruitment literature. An understanding of these wider issues will enable organisations and individuals to anticipate specific issues and problems and to preempt them in order to maximise the experience of F1 trainees in psychiatry. This will enable these doctors to develop a sound knowledge of mental disorders and begin to develop complex skills and behaviours conducive to embodying professionalism as a medic, which will be of value whatever specialty they eventually choose as a career.

\section{Acknowledgements}

We would like to thank Mr Paul Smith, Dr Lenny Cornwall and Dr Simon Sinclair for their valuable comments on earlier drafts of the manuscript, and Mr Bryan O'Leary and Ms Catherine Ebenezer for their support and encouragement in the writing of this article. We also thank numerous colleagues we have spoken with along the way, who have given practical suggestions in ways of optimising $\mathrm{F} 1$ posts in psychiatry. 


\section{MCQ answers}

$1 \mathrm{~b} \quad 2 \mathrm{~b} \quad 3 \mathrm{~d} \quad 4 \mathrm{a} \quad 5 \mathrm{e}$

\section{References}

Azer S (2005) The qualities of a good teacher: how can they be acquired and sustained? Journal of the Royal Society of Medicine 98: 67-9.

Bogg J, Gibbs T, Bundred P (2001) Training, job demands and mental health of pre-registration house officers. Medical Education 35: 590-5.

Brown TM, Addie K, Eagles JM (2007) Recruitment into psychiatry: views of consultants in Scotland. Psychiatric Bulletin 31: 411-3.

Brown T (2012) Recruitment Strategy 2011-2016. Royal College of Psychiatrists (http://www.rcpsych.ac.uk/pdf/Recruitment\%20 Strategy\%20-\%2010092013.pdf).

Collins J (2010) Foundation for Excellence: An Evaluation of the Foundation Programme. Medical Education England.

Dale J, Milner G (2009) New Ways not working? Psychiatrists' attitudes. Psychiatric Bulletin 33: 204-7.

Dein K, Livingston G, Bench C (2007) 'Why did I become a psychiatrist?': survey of consultant psychiatrists. Psychiatric Bulletin 31: 227-30.

Department of Health (2004) Modernising Medical Careers: The Next Steps. Department of Health.

Eagles JM, Wilson S, Murdoch JM, et al (2007) What impact do undergraduate experiences have upon recruitment into psychiatry? Psychiatric Bulletin 31: 70-2.

Ford JC (2010) If not, why not? Reasons why Canadian postgraduate trainees choose - or did not choose - to become pathologists. Human Pathology 41: 566-73.

Fothergill A, Edwards D, Burnard P (2004) Stress, burnout, coping and stress management in psychiatrists: findings from a systematic review. International Journal of Social Psychiatry 50: 54-65.

Firth-Cozens J, Moss F, Rayner C, et al (2000) The effect of 1-year rotations on stress in preregistration house officers. Hospital Medicine 61: 859-6.

Gabbay J, le May A (2011) Practice-Based Evidence for Healthcare: Clinical Mindlines. Routledge.

Gale R, Jackson G, Nicholls M (1992) How to run an induction meeting for house officers. BMJ 304: 1619-20.

General Medical Council (2009) Tomorrow's Doctors: Outcomes and Standards for Undergraduate Medical Education. GMC.

General Medical Council (2013) Good Medical Practice. GMC.

Goldacre MJ, Turner G, Fazel S, et al (2005) Career choices for psychiatry: national surveys of graduates of 1974-2000 from UK medical schools. British Journal of Psychiatry 186: 158-64.

Goldacre MJ, Fazel S, Smith F, et al (2013) Choice and rejection of psychiatry as a career: surveys of UK medical graduates from 1974 to 2009. British Journal of Psychiatry 202: 228-34.

Guthrie E, Tattan T, Williams E, et al (1999) Sources of stress, psychological distress and burnout in psychiatrists. Comparison of junior doctors, senior registrars and consultants. Psychiatric Bulletin 23: 207-12.

Harden R, Crosby J (2000) AMEE Guide No 20: The good teacher is more than a lecturer - the twelve roles of the teacher. Medical Teacher 22 : 334-47.

HM Government (2011) No Health Without Mental Health: A Cross Government Mental Health Outcomes Strategy for People of All Ages. HM Government.

Ho H, McConville P (2004) Who's happy with supervision? Psychiatric Bulletin 28: 87-90.

Hung T, Jarvis-Sellinger S, Ford JC (2011) Residency choices by graduating medical students: why not pathology? Human Pathology 42 : 802-7

Ip SW, Ko HS, Applegate KE (2010) Factors influencing career choice in radiology trainees in Queensland, Australia. Journal of Medical Imaging and Radiation Oncology 54: 93-9

Irvine D (1999) The performance of doctors: the new professionalism. Lancet 353: 1174-7.
Jochemsen-van der Leeuw HG, van Dijk N, van Etten-Jamaludin FS (2013) The attributes of the clinical trainer as a role model: a systematic review. Academic Medicine 88: 26-34.

Kelleher E, Campbell A (2011) A study of consultant psychiatrists response to patients' suicide. Irish Journal of Psychological Medicine 28: $35-7$.

Kelley TA, Brown J, Carney S (2013) Foundation Programme psychiatry placement and doctors' decision to pursue a career in psychiatry. Psychiatrist 37: 30-2.

Kennedy T, Regehr G, Ross Baker G, et al (2005) Progressive independence in clinical training: a tradition worth defending? Academic Medicine 80: S106-11.

Kilminster S, Cottrell D, Grant J, et al (2007) AMEE Guide No. 27: Effective educational and clinical supervision. Medical Teacher 29: 2-19.

Kozlowska K, Nunn K, Cousens P (1997) Training in psychiatry: an examination of trainee perceptions. Part 1. Australian and New Zealand Journal of Psychiatry 31: 628-40.

Kumar S, Hatcher S, Huggard P (2005) Burnout in psychiatrists: an etiological model. International Journal of Psychiatry in Medicine 35 : 405-16

Lambert TW, Davidson JM, Evans J, et al (2003) Doctors' reasons for rejecting initial choices of specialties as long-term careers. Medical Education 37: 312-8.

Lambert TW, Turner G, Fazel S, et al (2006) Reasons why some UK medical graduates who initially choose psychiatry do not pursue it as a long-term career. Psychological Medicine 36: 679-84.

Lowe J, Rands G (2012) Current position of psychiatry in UK foundation schools. Psychiatrist 36: 65-8.

MacDougall J, Drummond MJ (2005) The development of medical teachers: an enquiry into the learning histories of 10 experienced medical teachers. Medical Education 39: 1213-20.

Mahoney R, Cornelius K, McParland M, et al (2004) Shortage specialties: changes in career intentions from medical student to newly qualified doctor. Medical Teacher 26: 650-4.

Maidment R, Livingston G, Katona C, et al (2004) Change in attitudes to psychiatry and intention to pursue psychiatry as a career in newly qualified doctors: a follow-up of two cohorts of medical students. Medical Teacher 26: 565-9.

Malik A, White 0, Mitchell J, et al (2008) New Ways of Working and psychiatric trainees. Psychiatric Bulletin 32: 230-2.

Manassis K, Katz M, Lofchy J, et al (2006) Choosing a career in psychiatry: influential factors within a medical school program. Academic Psychiatry 30: $325-9$

McParland M, Noble L, Livingston G, et al (2003) The effect of a psychiatric attachment on students' attitudes to and the intention to pursue psychiatry as a career. Medical Education 37: 447-54.

Milstein JM, Raingruber BJ, Bennett SH, et al (2009) Burnout assessment in house officers: evaluation of an intervention to reduce stress. Medical Teacher 31: 338-41.

Moloney J, MacDonald J (2000) Psychiatric training in New Zealand. Australian and New Zealand Journal of Psychiatry 34: 146-53.

Mukherjee K, Maier M, Wessely S (2013) UK crisis in recruitment into psychiatric training. Psychiatrist 37: 210-4.

Munro Wickham J (2012) Supervision: an issue for supervisors and supervisees. Advances in Psychiatric Treatment 18: 416-7.

Paice E, Moss F, Heard S, et al (2002a) The relationship between preregistration house officers and their consultants. Medical Education 36: 26-34.

Paice E, Heard S, Moss F, et al (2002b) How important are role models in making good doctors? BMJ 325: 707-10.

Pidd SA (2003) Recruiting and retaining psychiatrists. Advances in Psychiatric Treatment 9: 405-11.

Ramirez AJ, Graham J, Richards MA, et al (1996) Mental health of hospital consultants: the effects of stress and satisfaction at work. Lancet 347: 724-8. 
Rathod S, Roy L, Ramsay M, et al (2000) A survey of stress in psychiatrists working in the Wessex Region. Psychiatric Bulletin 24: 133-6.

Rathod S, Mistry M, Ibbotson B, et al (2011) Stress in psychiatrists: coping with a decade of rapid change. Psychiatrist 35: 130-4.

Schmidt HG, Rotgans J, Yew EHJ (2011) The process of problem-based learning: what works and why. Medical Education 45: 792-806.

Scocco P, Toffol E, Pilotto E, et al (2012) Psychiatrists' emotional reactions to patient suicidal behavior. Journal of Psychiatric Practice 18: 94-108.

Shah P, Brown TM, Eagles JM (2011) Choosing psychiatry: factors influencing career choice among foundation doctors in Scotland. In Teaching Psychiatry to Undergraduates (eds T Brown, JM Eagles): 255-63. RCPsych Publications.

Stark P, Mitchell DA (2003) Bridging the gap - vocational trainee to senior house officer: a new induction course. British Dental Journal 194: $167-71$.

Stenfors-Hayes T, Hult H, Dahlgren LO (2011) What does it mean to be a good teacher and clinical supervisor in medical education? Advances in Health Sciences Education: Theory and Practice 16: 197-210.
St John-Smith P, McQueen D, Michael A, et al (2009) The trouble with NHS psychiatry in England. Psychiatric Bulletin 33: 219-25.

Sutkin G, Wagner E, Harris I, et al (2008) What makes a good clinical teacher in medicine? A review of the literature. Academic Medicine 83: 452-66

Taylor C, Graham J, Potts HWW, et al (2005) Changes in mental health of UK hospital consultants since the mid-1990s. Lancet 366: 742-4.

Tyssen R, Vaglum P (2002) Mental health problems amongst young doctors: an updated review of prospective studies. Harvard Review of Psychiatry 10: 154

UK Foundation Programme (2012) The UK Foundation Programme Curriculum 2012. UK Foundation Programme (http://www. foundationprogramme. nhs.uk/pages/home/curriculum-and-assessment/curriculum2012)

Ward SJ, Stanley P (1999a) Induction for senior house officers. Part 1: The hospital programme. Postgraduate Medical Journal 75: 346-50.

Ward SJ, Stanley P (1999b) Induction for senior house officers. Part 2: The departmental programme. Postgraduate Medical Journal 75: 401-4.

Welch J, Bridge C, Firth D, et al (2011) Improving psychiatry training in the Foundation Programme. Psychiatrist 35: 389-93.
MCQs

Select the single best option for each question stem

1 Which of the following statements is true regarding the issues that might arise for F1 doctors in their first year of medical practice:

a organisational factors such as frequently remaining in the same work base are likely to contribute to stress

b the general stressors accompanying the student-to-doctor transition are likely to be compounded for F1 psychiatrists by specific stressors related to the context of working in psychiatry

c F1 doctors often believe that they have too little administrative duties

d F1 doctors generally find it straightforward and unproblematic to develop a sense of professionalism

e the general stressors accompanying the student-to-doctor transition are not likely to be compounded for $\mathrm{F} 1$ psychiatrists by specific stressors related to the context of working in psychiatry.

2 Which of the following approaches may be useful for inducting new $\mathrm{F} 1$ doctors into psychiatry:

a do not encourage departing F1 doctors to be involved in the induction process for new F1 trainees

b provide guidance and support to help F1 doctors acquire core psychiatric clinical skills, but separate immediate practical induction from deeper educational and clinical induction c provide no specific guidance and support to help F1 doctors acquire psychiatric skills as this is not necessary

$\mathrm{d}$ induct F1 doctors into the immediate, practica necessities of their role and work base, while simultaneously providing deeper educational and clinical induction

e provide guidance and support to help F1 doctors acquire core psychiatric clinical skills but do not separate deeper educational and clinical induction from immediate, practical induction.

3 The relationship between consultant supervisor and $\mathrm{F} 1$ doctor is:

a less important to new graduates than their continuing relationships and support from their undergraduate medical tutors

b moderately important, but F1 doctors generally place more stress on the centrality of their relationship with ward nursing staff

c not at all critical and can make no difference between the F1 doctor starting out positively in their career or making the decision to leave medicine

$\mathrm{d}$ critical and can make the difference between the F1 doctor starting out positively in their career or making the decision to leave medicine

e moderately important, but F1 doctors generally place more stress on the centrality of their relationship with senior nursing staff.

4 Which of the following statements best represents how $\mathrm{F} 1$ doctors should receive supervision:

a it is highly appropriate for support and guidance to be offered by other members of the multidisciplinary team: formal clinical supervision should only be provided by more senior doctors

b it is not appropriate for support and guidance to be offered by other members of the multidisciplinary team: formal clinical supervision should only be provided by more senior doctors

c it is highly appropriate for support and guidance to be offered by other members of the multidisciplinary team: formal clinical supervision should only be provided by clinical psychologists

d it is highly appropriate for support and guidance to be offered by other members of the multidisciplinary team: formal clinical supervision should only be provided by nurses

e it is highly appropriate for support and guidance to be offered by other members of the multidisciplinary team: formal clinical supervision should only be provided by other junior doctors.

5 Which of the following skills conducive to contemporary medical professionalism may be successfully developed by F1 doctors in a psychiatry placement:

a a balanced relationship between themselves as medics and their patients

b skills in managing patients with medically unexplained symptoms

c working effectively within multidisciplinary teams

$d$ treating patients with dignity and avoiding discrimination

e all of these options. 